\title{
Effect of Light and Water on the Degradation of Asphalt
}

\author{
L. R. Kleinschmidt* and H. R. Snoke
}

(April 14, 1959)

\begin{abstract}
Coatings prepared from two blown petroleum asphalts in a thickness range of 0.002 to 0.04 inches were exposed to accelerated test conditions and outdoors. When exposed to light only, a surface film, insoluble in common asphalt solvents, was formed. The formation of this surface film was accompanied by a gain in weight of the coatings, apparently due to an oxygen pickup. This surface film retarded further degradation of the maltenes during the exposures made to light only. When the coatings were immersed in water after exposure, or sprayed with water during exposure, or exposed outdoors, they lost weight. These decreases in weight were found to be in part due to the extraction of water-soluble, lightdegraded material. Their magnitudes were dependent upon the asphalt exposed, the thickness of the exposed coatings, and the exposure conditions. The relationship between the losses in weight and water-soluble material, when considered in conjunction with the oxygen content of the asphalts and the water-soluble materials, indicated that volatile degradation products were also formed.

When the surface skin formed by the action of light was partially removed by washing with water, percentage decreases were noted in the water-white oils, dark oils, and asphaltic resins. Since these decreases were unequal in magnitude and since the losses in weight were dependent on the thickness of the coating, it was concluded that light-degradable components of the asphalt had migrated to the surface to replace degraded material that had been washed away.
\end{abstract}

\section{Introduction}

The National Bureau of Standards, in conjunction with the Asphalt Roofing Industry Bureau, ${ }^{1}$ is engaged in a study of the constitution and degradation of asphalt. Papers published recently in connection with this work describe methods for the preparation of test specimens [1,2], ${ }^{2}$ the behavior of asphalt coatings when exposed to various accelerated test conditions $[3,4]$, a chromatographic method for separating asphalt into groups of distinctive components [5], a study of the water-soluble degradation products of asphalt [6], the effect of mineral additives on the durability of coating-grade asphalts [7], and changes in the components of asphalt during the blowing operation [8]. This paper deals with a photochemical reaction occurring at the surface of asphalt on exposure to light and a combination of light and water.

\section{Materials}

From the three basic asphalts described by Greenfeld [7], asphalts Nos. I and III were selected for this study because previous work had indicated that asphalts II and III behaved similarly and were more resistant to weathering than asphalt I.

Products ${ }^{3} 1$ of asphalts I and III, with softening points ${ }^{4}$ of $189^{\circ}$ and $190^{\circ} \mathrm{F}$, and penetrations ${ }^{5}$ of 28 and 22 , respectively, were used for the outdoor

\footnotetext{
* Deceased.

An association of manufacturers of roofing materials that has supported research at NBS under the Research Associate Plan for more than 30 years.

${ }_{2}^{2}$ Figures in brackets indicate the literature references at the end of this paper. 3 Figures in brackets indicate the literature references at the end of this paper.
An asphalt product is defined [7] as an asphalt blown to a desired softening point.

Softening Point, Ring and Ball, A.S.T.M. Method D36-26.

Penetration of Bituminous Materials, A.S.T.M. Method D5-52.
}

exposures and are identified hereafter as asphalts I-1 and III-1. Products 4 and 5 of these asphalts, respectively, with softening points of $223^{\circ}$ and $232^{\circ} \mathrm{F}$, and penetrations of 17 and 16 , respectively, were used for the accelerated weathering exposures and are referred to hereafter as asphalts I-4 and III-5.

\section{Exposure Methods}

Exposure specimens were prepared by the hydraulic press or spinning methods described in references [1] and [2]. The hydraulic press method was used to prepare the 0.025 -in. coatings for studies of changes in components. All other specimens were prepared by the spinning method.

The physical characteristics of the accelerated weathering machines and the spectral distribution range of the light ${ }^{6}$ from the arc lamp are described in Tentative Recommended Practice for Accelerated Weathering Test of Bituminous Materials, A.S.T.M. Designation D529-39T. The drums holding the specimens revolved at the rate of $1 \mathrm{rpm}$. The spray units consisted of 4 mist-type spray jets, equally spaced on a vertical feeder. The spray units delivered approximately $20 \mathrm{gal} / \mathrm{hr}$ of demineralized water at a temperature of $77^{\circ} \pm 3^{\circ} \mathrm{F}$.

The exposure conditions, cycles 1 to 4 , are outlined in table 1. The outdoor exposures were made on the roof of the Industrial Building, National Bureau of Standards, Washington, D.C. The specimens were exposed on racks at an inclination of $45 \mathrm{deg}$, facing south.

${ }^{6}$ Light as used in this paper refers to the radiant energy from a low-intensity, enclosed carbon are light. 
TABLE 1. Accelerated exposure cycles

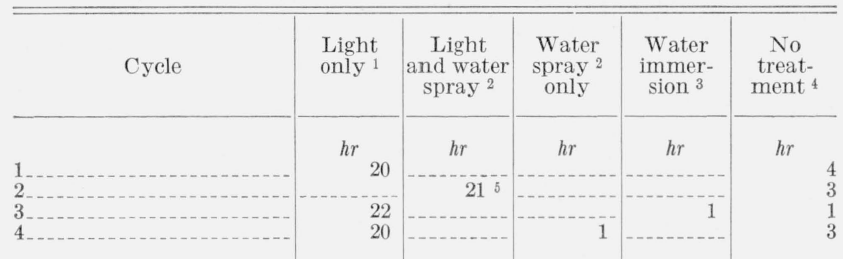

Temperature of specimens, $140^{\circ} \pm 3^{\circ} \mathrm{F}$

2 The spray unit consisted of four mist-type spray jets, equally spaced on a vertical feeder. The spray jets delivered approximately 20 gal of water at a temperature of $77^{\circ} \pm 3^{\circ} \mathrm{F}$ each hour. Each specimen was directly under the spray jets for about 2 sec each minute of the spray periods.

3 One gallon of distilled water used as the immersion bath for each set of eight

test specimens for each 240 -hr exposure period.

The specimens were exposed for 51 min to light only, followed by a 9 -min exposure to light and water each hour.

\section{Procedures and Results}

\subsection{Accelerated Exposures}

\section{a. Light, Cycle 1}

During the first $20 \mathrm{hr}$ of exposure to light only, there were formed on the exposed surfaces of the coatings thin, continuous films of material insoluble in carbon tetrachloride, chloroform, and benzene, in which the unexposed asphalts were soluble.

Figure 1 illustrates the appearance of a specimen prepared from asphalt $\mathrm{I}-4$, in a coating thickness of $0.012 \mathrm{in}$., which had been exposed to $120 \mathrm{hr}$ of cycle 1. A metal shield held $1 / 4$ in. from the coating protected the lower half of the specimen from light during its exposure.

Four specimens prepared from asphalt I-4 in a coating thickness of 0.012 in. were exposed for 24, 48, 96, and $140 \mathrm{hr}$. After exposure the coatings were removed from the aluminum panels by digest-

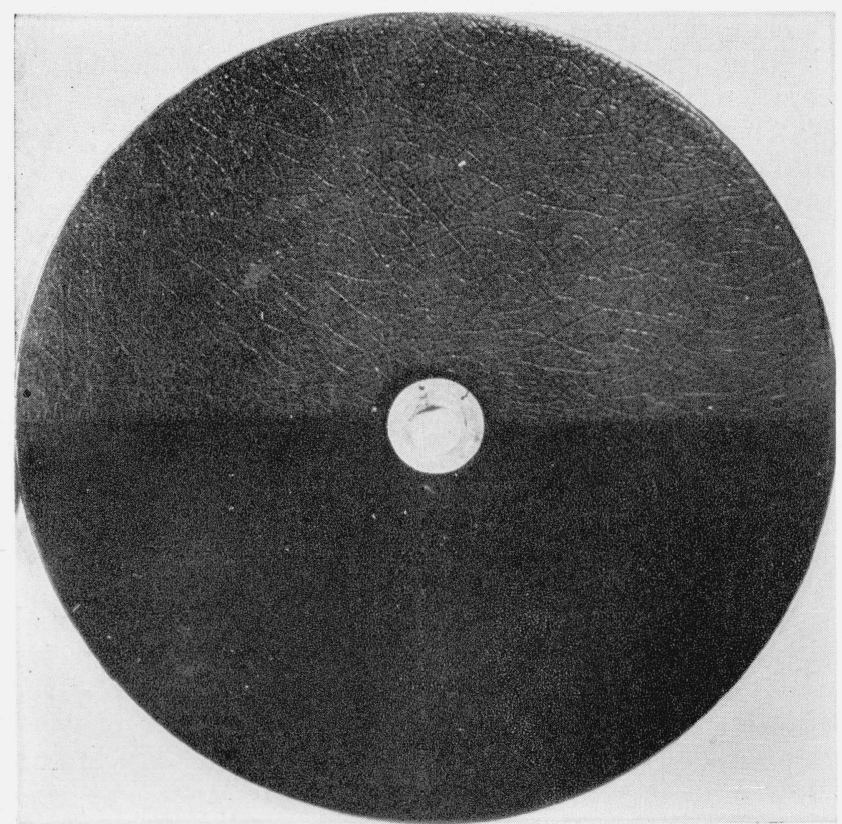

Figure 1. Coating of asphalt I-4,0.01\%-in. thick.

Light area exposed to $120 \mathrm{hr}$ of cycle 1 (light only). Dark area masked. ing the specimens in $n$-pentane. The $n$-pentaneinsoluble material from the coatings was recovered by filtration, using a porcelain bitumen crucible with an asbestos mat. This $n$-pentane-insoluble material when washed with chloroform yielded small amounts of insoluble material. This insoluble material was yellowish-brown in color, sheetlike in form, and weighed $3.0,2.7,2.8$, and $2.6 \mathrm{gr} / \mathrm{ft}^{2}$, respectively. It contained 22 percent oxygen.?

Fifteen specimens prepared from asphalt I-4 in a coating thickness of 0.025 in. were exposed to cycle 1. Three specimens were removed and examined for changes in weight and distribution of components [5] after $240,480,720,1,080$, and $1,440 \mathrm{hr}$ of exposure. These data, based on the weights of the unexposed coatings, are reported in table 2 .

The refractive indices of the water-white and dark oils separated at the five intervals of exposure, reported in table 3 , were determined with an Abbetype refractometer for the wavelength of the sodium$\mathrm{D}$ line.

TABLE 2. Changes in weight and distribution of components of specimens exposed to cycles 1 and 3

\begin{tabular}{|c|c|c|c|c|c|c|c|c|c|}
\hline \multirow{3}{*}{$\begin{array}{l}\text { Exposure } \\
\text { Gain in weight } \\
\%_{1}^{1}\end{array}$} & \multicolumn{9}{|c|}{ Cycle 1} \\
\hline & 0 & 240 & 480 & 720 & 1,080 & 1,440 & & & \\
\hline & & 0.2 & 0.1 & 0.1 & 0.1 & 0.0 & & & \\
\hline$n$-pentane-insoluble ma- & 41,8 & 45,9 & 46.8 & 46.4 & 47.1 & 47.8 & & & \\
\hline Water-white oils & $\begin{array}{l}41.8 \\
27.4\end{array}$ & $\begin{array}{l}40.9 \\
24.1\end{array}$ & $\begin{array}{l}46.8 \\
23.8\end{array}$ & $\begin{array}{l}46.4 \\
23.8\end{array}$ & $\begin{array}{l}47.1 \\
23.8\end{array}$ & $\begin{array}{l}47.8 \\
24.1\end{array}$ & & & \\
\hline Dark oils & 18.2 & 14. 2 & 13.4 & 13. 9 & 13.4 & 13. 7 & & & \\
\hline Asphaltic resins. & 10.3 & 11.7 & 11.9 & 11.6 & 11.1 & 11.2 & & & \\
\hline \multirow[t]{2}{*}{ Total recovery . .... \% } & 97.7 & 95.9 & 95.9 & 95.7 & 95.4 & 96.8 & & & \\
\hline & \multicolumn{9}{|c|}{ Cycle 3} \\
\hline Exposure & 0 & 216 & 432 & 648 & 984 & 1,296 & 1,874 & 2,736 & 3,816 \\
\hline Loss in weight & 0 & 1.1 & 3.1 & 5.9 & 9.7 & 12.9 & 17.5 & 20.7 & 24. \\
\hline$n$-pentane-insoluble ma- & & & & & & & & & \\
\hline Water-white oils & $\begin{array}{l}41.8 \\
27.4\end{array}$ & $\begin{array}{l}40.9 \\
24.5\end{array}$ & $\begin{array}{l}48.5 \\
22.9\end{array}$ & $\begin{array}{l}48.7 \\
21.6\end{array}$ & $\begin{array}{l}48.7 \\
20.3\end{array}$ & $\begin{array}{l}48.9 \\
18.5\end{array}$ & $\begin{array}{l}48.9 \\
17.9\end{array}$ & $\begin{array}{l}47.6 \\
17.8\end{array}$ & $\begin{array}{l}47.0 \\
15.7\end{array}$ \\
\hline Dark oils & 18.2 & 13.6 & 11. 3 & 10.0 & 8.9 & 8.1 & 7. 0 & 6.9 & \\
\hline Asphaltic resins & 10.3 & 11.4 & 11.4 & 10.6 & 9.6 & 9.1 & 8.0 & 6. 2 & 6.2 \\
\hline Total recovery & 97.7 & 97.5 & 97.2 & 96.8 & 97. 2 & 97.5 & 99.1 & 99. 2 & 98.5 \\
\hline
\end{tabular}

The gain in weight for the 240-hr exposure period was the average gain of 15 specimens. For each successive inspection period the gain in weight was the average gain of three fewer specimens than the previous period. The distribution of components reported for each exposure period was the average for three of component
specimens.

specimens. spccimens. For each successive period the loss in weight was the average loss of three fewer specimens than for the previous period. The distribution of com. ponents reported for each exposure period was the average for three specimens.

TAвLE 3. Refractive indices of water-white and dark oils recovered from specimens exposed to cycles 1 and $3^{1}$

\begin{tabular}{|c|c|c|c|c|c|}
\hline \multirow[b]{2}{*}{$\begin{array}{l}\text { Expo- } \\
\text { sure }\end{array}$} & \multicolumn{2}{|c|}{ Cycle 1} & \multirow{2}{*}{$\begin{array}{l}\text { Expo- } \\
\text { sure }\end{array}$} & \multicolumn{2}{|c|}{ Cycle 3} \\
\hline & $\begin{array}{l}\text { Water- } \\
\text { white } \\
\text { oils }\end{array}$ & Dark oils & & $\begin{array}{c}\text { Water- } \\
\text { white } \\
\text { oils }\end{array}$ & Dark oils \\
\hline \begin{tabular}{r}
\multicolumn{1}{c}{$h r$} \\
0 \\
240 \\
480 \\
720 \\
1,080 \\
1,440 \\
2,040 \\
3,000 \\
4,200
\end{tabular} & $\begin{array}{r}\text { at } 77^{\circ} F \\
1.4982 \\
1.4954 \\
1.4956 \\
1.4952 \\
1.4952 \\
1.4952\end{array}$ & 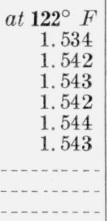 & $\begin{array}{r}h r . \\
0 \\
216 \\
432 \\
648 \\
984 \\
1,293 \\
1,874 \\
2,736 \\
3,816\end{array}$ & $\begin{array}{r}\text { at } 77^{\circ} F \\
1.4982 \\
1.4969 \\
1.4952 \\
1.4940 \\
1.4932 \\
1.4924 \\
1.4912 \\
1.4892 \\
1.4888\end{array}$ & at $\begin{array}{r}122^{\circ} F \\
1.554 \\
1.554 \\
1.548 \\
1.537 \\
1.535 \\
1.533 \\
1.527 \\
1.522 \\
1.516\end{array}$ \\
\hline
\end{tabular}

1 Determined with an Abbe-type refractometer for the wavelength of the sodium-D line.

${ }^{7}$ Determined by Shigeru Ishihara, Research Associate, Asphalt Roofing Industry Bureau. 


\section{b. Light and Water Spray, Cycle 2}

Figure 2 illustrates the appearance of a specimen which has been exposed to $120 \mathrm{hr}$ of cycle 2 . It had been prepared from the same asphalt and in the same coating thickness as that used in preparing the specimen which had been exposed to light only (fig. 1). The shield which protected the lower half of the specimen from light was mounted approximately $1 / 4$ in. from the coating, which permitted water to flow over the entire coating during the spray periods. Only the light activated portion of the coating was matted. No cracking or grooving occurred.

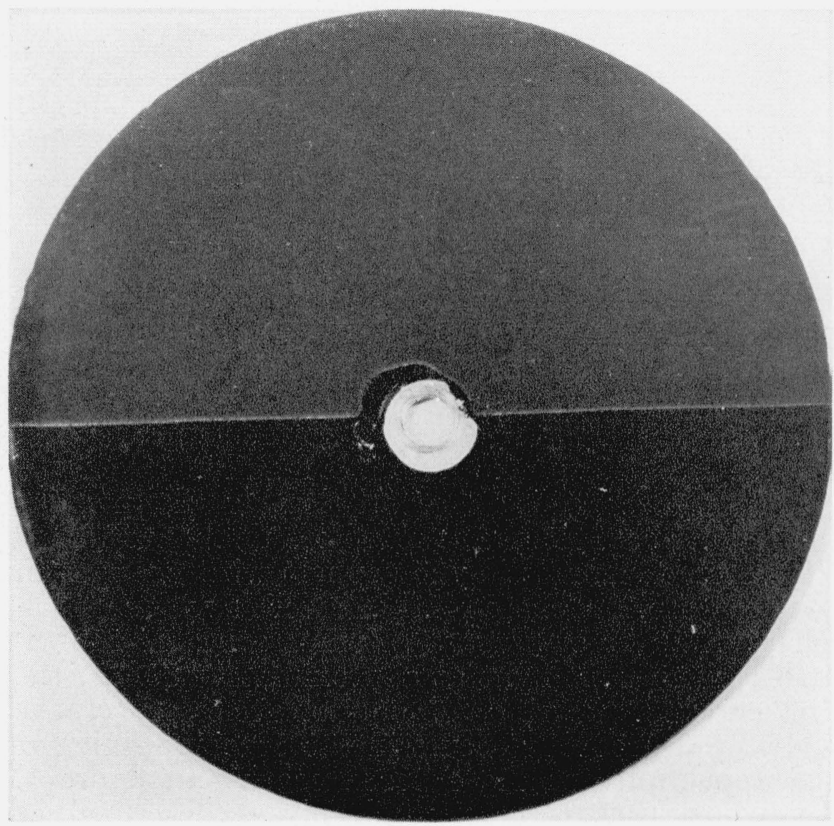

Figure 2. Coating of asphalt I-4, 0.012-in. thick.

Light area exposed to $120 \mathrm{hr}$ of cycle 2 (light and water spray). Dark area masked from light, but exposed to water spray.

Figure 3 illustrates the losses in weight of 15 coatings of asphalt I-4 and 9 coatings of asphalt III-5, varying in thickness from 0.005 to 0.04 in., at selected intervals up to $1,440 \mathrm{hr}$ of cycle 2 .

\section{c. Light and Water Immersion, Cycle 3}

In table 4 are reported the losses in weight and the amounts of water-soluble degradation products recovered after $216,432,648,984$, and $1,296 \mathrm{hr}$ of exposure to cycle 3 , of eight specimens prepared from each of the Nos. I-4 and III-5 asphalts. The coatings ranged from 0.012 to 0.017 in. in thickness. One gallon of distilled water was used as the immersion bath for each set of eight test specimens for each 216-hr exposure period. The water-soluble materials leached from the coatings gave the immersion liquids a deep amber color, with only traces of suspended material. The $p \mathrm{H}$ of the immersion liquids at the end of the 984 to $1,296 \mathrm{hr}$ exposure period was 3.18 for both asphalts I-4 and III -5 .
TABLE 4. Loss in weight and weights of recovered water-extracted degradation products formed on the exposure of asphalts $I-4$ and $I I I-5$ to cycle $3^{1}$

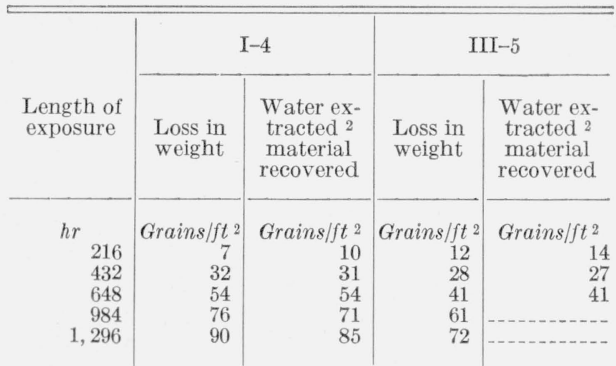

The loss in weight of the coatings and weights of the water-extracted material recovered were the averages of 8 specimens whose coating thickness ranged from 0.012 to $0.017 \mathrm{in}$.

2 Oven-dried for $1 \mathrm{hr}$ at $212^{\circ} \mathrm{F}$ before weighing.

The immersion liquids were filtered before being evaporated to dryness. The residues from these immersion liquids were oven-dried for $1 \mathrm{hr}$ at $212^{\circ} \mathrm{F}$ before being weighed. After oven-drying, the residues were no longer completely soluble in water; they were, however, soluble in dilute alkali solutions. Direct oxygen determinations were made ${ }^{7}$ on the water-soluble material formed during the 984- to 1,296-hr exposure period.

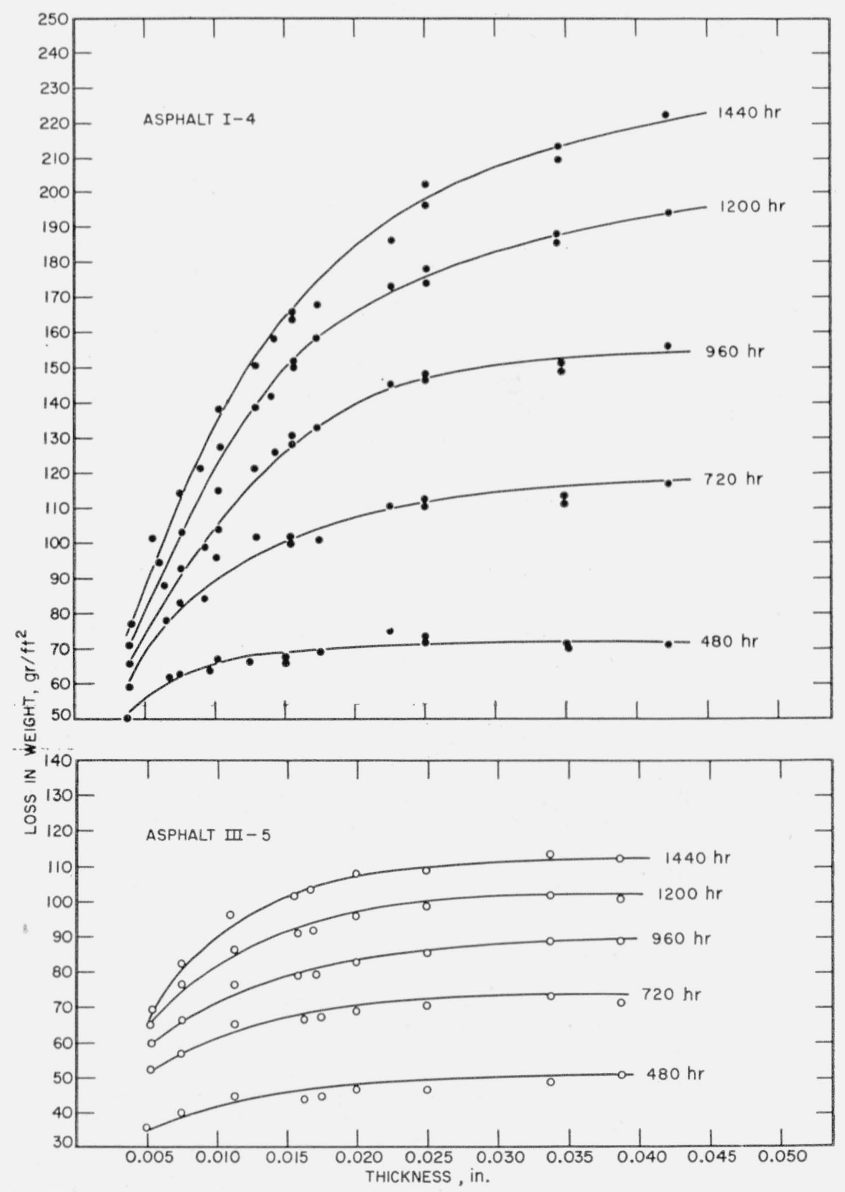

FIGURE 3. Loss in weight of coatings prepared from asphalts I-4 and III-5 at 240-hr intervals of exposure to cycle 2. 
Twenty-four specimens prepared from asphalt I-4 in a coating thickness of $0.025 \mathrm{in}$. were exposed to cycle 3. Three specimens were removed and examined for changes in weight and distribution of components [5] after 216, 432, 648, 984, 1,296, $1,874,2,736$, and $3,816 \mathrm{hr}$ of exposure. These data, based on the weights of the unexposed coatings, are reported in table 2. The refractive indices of the water-white and dark oils separated at the 8 intervals of exposure were determined with an Abbe-type refractometer for the wavelength of the sodium-D line and are reported in table 3.

\section{d. Light, Followed by Water Spray, Cycle 4}

In figure 4 are illustrated the losses in weight of four coatings each of asphalts I-4 and III-5, varying in thickness from 0.003 to 0.009 in., at selected intervals up to $1,920 \mathrm{hr}$ of exposure to cycle 4.

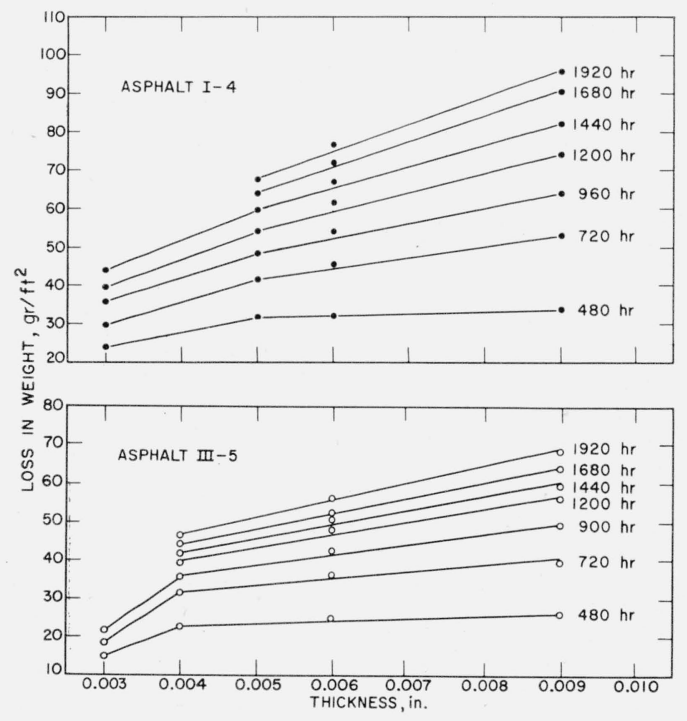

Figure 4. Loss in weight of coatings prepared from asphalts $I-4$ and $I I I-5$ at $240-h r$ intervals to cycle 4.

\subsection{Outdoor Exposures}

Figure 5 illustrates the losses in weight of 15 coatings of asphalt I-1 and 11 coatings of asphalt III-1, varying in thickness from 0.003 to 0.040 in., after 30 months of exposure outdoors in Washington, D.C.

\section{Discussion of Results}

\subsection{Effect of Light Alone}

It has been known for some time that asphalt exposed to light, in an oxidizing atmosphere, develops a thin surface film which is insoluble in common asphalt solvents such as chloroform, carbon tetrachloride, and benzene. Joseph N. Niepce [9] in 1816 reported that some natural asphalts became insoluble

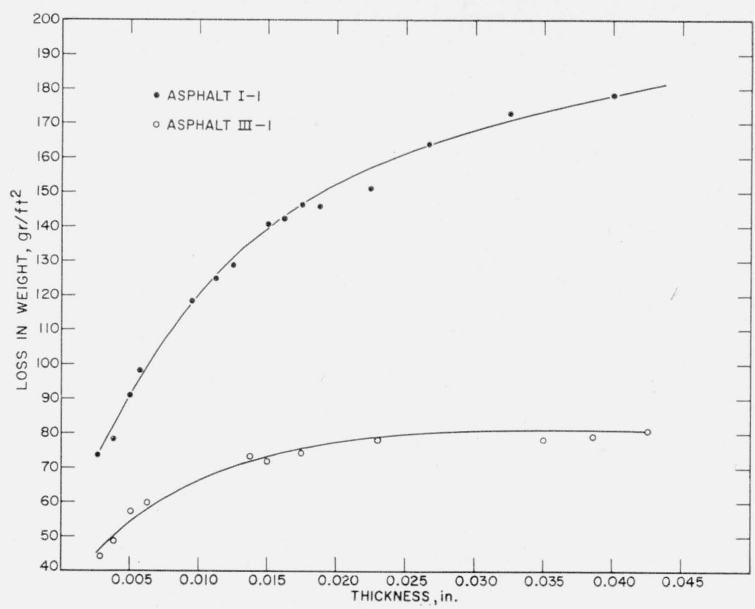

FIgURE 5. Loss in weight of asphalt coatings prepared from asphalts $I-1$ and $I I I-1$ after 30 months of exposure outdoors.

in certain asphalt solvents such as chloroform and carbon disulphide on exposure to light. This phenomenon has been used to a limited extent in photoengraving.

This surface film has been likened in its physical behavior to the film of tissue formed on the skin surface of a person who sunburns readily.

The surface film is apparently less ductile than the underlying asphalt and is therefore unable to follow the volume changes in the asphalt with changes in temperature. Consequently, after two or three cycles of $20 \mathrm{hr}$ of light at a temperature of $140^{\circ} \mathrm{F}$ and $4 \mathrm{hr}$ without light at approximately $80^{\circ} \mathrm{F}$, the film cracked. During subsequent cycles the cracks widen and grooving occurs in the coating, giving it the appearance of the exposed coating in figure 1 . A surface that is grooved deeply is described as "alligatored". With long-continued exposure this grooving will extend through the entire coating.

The gain in weight exluibited by the specimens exposed to light alone was mainly due to oxygen pick-up in the formation of light-degraded, watersoluble materials.

\subsection{Effect of Light and Water}

In 1936, Strieter and Snoke [10] demonstrated, by their exposures of asphalts in sealed tubes, that both oxygen and light were necessary for that part of the degradation process which resulted in the formation of water-soluble materials. They reported that the water-soluble materials were in part ketonic acids and that they reduced Fehling's solution. Evidence of the formation of water-soluble degradation products in outdoor exposures is found in the discoloration of standing water on roofs surfaced with asphalt, and its acidic nature is shown by the etching of metal flashings and gutters used with such roofs.

A part of the surface film insoluble in common asphalt solvents formed by the action of light on asphalt surfaces is soluble in water. Consequently, when this material is removed, either by spraying 
with water or by immersing the specimen in water, no grooving of the coating occurs. Instead, the surface assumes the matte appearance shown by the light-exposed section of the specimen shown in figure 2 .

\section{a. Relation Between Loss in Weight and Water-Soluble Material Recovered}

The data in table 4 show that the amount of watersoluble material recovered from asphalt coatings of approximately the same thickness, after exposure to cycle 3 , is roughly equivalent to the loss in weight of the specimens. The oxygen content of the unexposed asphalt was approximately 2 percent; that of the oven-dried, water-soluble residue was approximately 35 percent. This difference in oxygen content, considered in conjunction with the relatively close agreement between the weight loss and water-soluble material recovered, indicates that other degradation products, probably volatile in nature, accompanied the formation of the water-soluble degradation products. This is in keeping with the findings of Thurston and Knowles [11], who reported that carbon dioxide and water were liberated and oxygen was absorbed when asphalt components in an oxygen atmosphere, in sealed tubes, were exposed to sunlamps.

\section{b. Relation Between Loss in Weight and Thickness of Coatings}

All of the data collected on exposures of asphalt coatings to cycles 2 and 4 and outdoors (figs. 3, 4 , and 5) show that, for equal periods of exposure, the loss in weight per unit area exposed increased as the thickness of the coatings increased, and varied with different asphalts. If weathering were a simple process of erosion, the loss in weight should be independent of the coating thickness, though differences among asphalts could be expected.

The greater loss in weight by the thicker coatings could be explained by light and oxygen penetration into the coatings if these penetrated readily. However, Pfeiffer [12] reported that the light intensity was reduced to about one percent at a depth of $50 \mu$ in a layer of bitumen and that oxygen diffuses into it at a very low rate.

It seems reasonable to assume that the conversion of light-susceptible material on the surface to watersoluble material, and the loss of this material by washing, would tend to unbalance the distribution of components in the system. Migration of components in an attempt to restore equilibrium would follow. Since the thicker coatings contained more of the light-susceptible components, they would produce the greater losses in weight on long exposure.

Migration of components within an asphalt has been recognized previously. Federal Specification SS-A-666, Asphalt for Built-up Roofing, Waterproofing and Damp-proofing, issued in 1933, contains a requirement that when freshly melted asphalt is stored for one week in a closed container "its surface shall not become dull or show any separation of oil, grease, paraffin scale, or similar material". The American Society for Testing Materials has published "Tentative Method of Test for Staining Properties of Asphalts"
(Modified Pressure Method D1328), to determine the tendency of oils to exude from asphalts. Oliensis [13] in his book, Exudation and Allied Reactions Between Bitumens discusses the movement of the maltenes within and between asphalts.

\section{c. Effects of Exposure to Light and Light and Water on the} Distribution of Components

Specimens prepared from asphalt I-4 in a coating thickness of $0.025 \mathrm{in}$. behaved similarly to the thinner coatings as regards gains in weight and the formation of the surface skin when exposed to light only.

Significant gains in weight and changes in percentage distribution of components were found only during the first $240 \mathrm{hr}$ of exposure to light. Similarly, it was only during that period that decreases were found in the refractive indices of the water-white and dark oils. Specimens examined after 480, 720, 1,080, and $1,440 \mathrm{hr}$ of exposure showed no appreciable changes in the percentage distribution of components, gains in weight, or changes in the refractive index of water-white and dark oils over those noted for the 240-hr exposure period. The surface skin formed during the initial period of exposure apparently served as a shield to prevent further degradation of the coating by light.

Losses instead of gains in weight were found during the first $216 \mathrm{hr}$ of exposure to light and water. During this period the changes in the percentage distribution of components were essentially the same as those noted during the initial period of exposure to light only. However, after this period, the effects of water in conjunction with light became more and more apparent.

Specimens exposed to cycle 3 showed progressive increases in loss in weight and decreases in the percentage of water-white and dark oils at the 432-, 648-, 984-, 1,296-, 1,874-, 2,736-, and 3,816-hr exposure intervals. Progressive decreases occurred in the percentages of asphaltic resins after the 432-hr exposure period. Refractive indices of the water-white and dark oils also showed progressive decreases during the long exposure. After the 216-hr exposure, the percentage of matter insoluble in $n$-pentane remained essentially constant.

The lack of change in the percentage of matter insoluble in $n$-pentane and the progressive loss in weight of the other components can be taken as further proof of the migration hypothesis described under 5.2.b. Relation Between Loss in Weight and Thickness of Film.

Assuming a gel or sol structure for the asphalt, either structure would permit free movement of the maltenes. Degradation of the maltenes at the surface and removal of the light-degraded material by washing would unbalance the system. In an attempt to restore equilibrium, light-susceptible materials would move to the surface to replace those degraded and removed.

The unequal percentage decreases of the waterwhite and dark oils and asphaltic resins indicated a selective rather than an overall degradation of these components. A selective degradation of water- 
white and dark oils is indicated also by the progressive decrease of the refractive index of the oils recovered from coatings exposed to cycle 3 . Oils recovered from coatings exposed to cycle 1, light only, showed no appreciable change in refractive index after exposure for $240 \mathrm{hr}$.

\section{Conclusions}

Asphalt coatings exposed to radiant energy from the enclosed, low-intensity carbon arc lamp gained weight during the early periods of exposure. The gain in weight was accompanied by the formation of a thin surface film insoluble in solvents that are normally used to dissolve asphalts. This surface film, isolated with $n$-pentane and chloroform, was sheetlike and yellowish-brown in color and contained approximately 22 percent oxygen.

Water-soluble material was recovered from coatings on which the surface film had formed. The water-soluble material contained 35 percent of oxygen; the original asphalts approximately 2 percent, indicating that the film formation was a lightinduced oxidation reaction, which would account for the gain in weight of the coatings exposed to light only. The close agreement between the amounts of water-soluble materials recovered and the loss in weight of the coatings, when considered in relation to the oxygen content of the asphalts and the watersoluble degradation products, indicated that volatile degradation products were also formed.

The loss in weight resulting from the exposures to combinations of light and water, either by accelerated or outdoor exposure, was dependent upon the asphalt exposed, the exposure conditions and the thickness of the exposed coatings. The actual loss in weight of the coatings increased as the coating thickness increased.

The percentages of $n$-pentane-insoluble material determined during the exposures of the specimens to light and water in cycle 3 , when considered in conjunction with the weight losses, indicated a gel or sol structure of the coatings through which the maltenes could migrate. When light-susceptible components at the surfaces of the coatings were degraded by light and oxygen and removed as water-soluble material, the structure of the coatings became unbalanced. To restore an equilibrium in the coatings, certain components of the maltenes migrated toward the surfaces of the coatings. The differences in the percentage decreases in the water-white oils, dark oils and asphaltic resins indicated a different rate of migration of these components rather than an overall degradation. The refractive indices determined on the water-white and dark oils recovered from the specimens which had been exposed to cycle 3 showed progressive decreases which indicated also a selective degradation within these two groups of components.

The authors are indebted to S. H. Greenfeld, J. P. Falzone, and S. Ishihara, research associates for the Asphalt Roofing Industry Bureau, for the preparation and exposure of the 0.025 -in. thick coatings used in the component studies and the stimulating discussions that helped to develop many of the concepts proposed in this paper.

\section{References}

[1] S. H. Greenfeld, A method of preparing uniform films of bituminous materials, Am. Soc. Testing Materials Bull. 194, 50 (1953).

[2] L. R. Kleinschmidt, Preparation of bituminous films by spinning, Am. Soc. Testing Materials Bull. 193, 53 (1953).

[3] S. H. Greenfeld, Effects of thermal shock on the durability of asphalt coatings under accelerated test, Am. Soc. Testing Materials Bull. 193, 46 (1953).

[4] L. R. Kleinschmidt and S. H. Greenfeld, Influence of exposure conditions on the accelerated durability testing of asphalt, Am. Soc. Testing Materials Bull. 213, 69 (1956).

[5] L. R. Kleinschmidt, Chromatographic method for the fractionation of asphalt into distinctive groups of components, J. Research NBS 54, 163 (1955) RP2577.

[6] Alan Schriesheim and S. H. Greenfeld, Water-soluble degradation products of asphalt, Am. Soc. Testing Materials Bull. 220, 43 (1957).

[7] S. H. Greenfeld, Effect of mineral additives on the durability of coating-grade roofing asphalts, NBS Building Materials and Structures Report 147 (1956).

[8] L. R. Kleinschmidt and H. R. Snoke, Changes in the components of asphalt during the blowing operation, J. Research NBS 60, 169 (1958) RP2835.

[9] F. Elder, Geschichte der Photographie (1905).

10] O. G. Strieter and H. R. Snoke, A modified accelerated weathering test for asphalts and other materials, J. Research NBS 16, 481 (1936) RP886.

[11] R. R. Thurston and E. C. Knowles, Asphalt and its constituents, oxidation at surface temperatures, Ind. Eng. Chem. 33, 320 (1941).

[12] J. P. H. Pfeiffer, The properties of asphaltic bitumens, 1st ed. Elsevier Publishing Co., Inc., New York, N.Y. (1950).

[13] G. L. Oliensis, Exudation and allied reactions between bitumens (Forest Publishing Co., Forest Park, Ill., 1947).

Washington, D.C.

(Paper 63C1-3) 